\title{
ABSCESO MEDIASTÍNICO CON EXTENSIÓN ESPONTÁNEA A TRAVÉS DE LA PARED TORÁCICA*
}

\author{
Drs. Marcelo Parra N. ${ }^{1}$, José Gantz V. ${ }^{2}$, José Ortega S. ${ }^{1}$, \\ Raúl Berríos S. ${ }^{1}$, Giancarlo Schiappacasse F. ${ }^{3}$
}

1 Equipo de Cirugía de Tórax.

2 Equipo Cirugía General.

3 Servicio de Imágenes.

Hospital Padre Hurtado, Facultad de Medicina Clínica Alemana-Universidad del Desarrollo.

Santiago, Chile.

\section{Abstract}

\section{Mediastinal abscess with spontaneous across chest wall extension}

Introduction: Mediastinal abscess (MA) is a rare disease in the adult population. Generally presents as a systemic inflammatory response syndrome (SIRS) with high morbidity and mortality. The prognosis improves with an early diagnosis associated with an aggressive surgical drainage. Clinical case: We report a clinical case with a MA with an unusual spontaneous extension across the chest wall.

Key words: Mediastinic abscess, mediastinitis, descending necrotizing mediastinitis.

\section{Resumen}

Introducción: Los abscesos mediastínicos (AM) son una patología poco frecuente en la población adulta. Su presentación clínica más habitual es la de un síndrome de respuesta inflamatoria sistémica (SIRS) con una elevada morbimortalidad. Su pronóstico mejora con un diagnóstico temprano asociado a un drenaje quirúrgico agresivo y precoz. Caso clínico: Presentamos un caso clínico de un AM con una inusual extensión espontánea a través de la pared torácica.

Palabras clave: Absceso Mediastínico, mediastinitis, mediastinitis necrotizante descendente.

\section{Introducción}

Los abscesos mediastínicos (AM) son una patología poco frecuente en la población adulta. La literatura nacional e internacional se limita a la presentación de series de casos, siendo el primero el reporte de Aronovitch en 1945 cuando publica dos casos $^{1}$. Al revisar la literatura no siempre es posible separar los cuadros clínicos de AM de las mediastinitis, ya que estos pueden ser distintas entidades

*Recibido el 22 de mayo de 2014 y aceptado para publicación el 24 de junio de 2014.

Los autores no refieren conflictos de interés.

Correspondencia: Dr. Marcelo Parra N. mfparra@gmail.com 
clínicas, o bien ser etapas de una misma enfermedad, habiendo casos donde pueden coexistir. Entre sus causas más frecuentes encontramos los AM secundarios a cirugía cardíaca, perforación esofágica y abscesos dentarios o retro faríngeos (mediastinitis descendentes). Otras causas descritas en la literatura de AM son la infección por vía hematógena de colecciones mediastínicas previas (quistes y hematomas); también existen AM posteriores a un trauma (generalmente penetrante) de la región cervical y/o torácica. Menos frecuentemente están los AM causados por la complicación de procesos crónicos como la tuberculosis, histoplasmosis, sarcoidosis, el cáncer o la radioterapia del tórax. Finalmente, queda un pequeño grupo en que su origen es desconocido ${ }^{2,3}$. Su presentación clínica más habitual ocurre con una escasa sintomatología torácica, que sin embargo, se traduce en un síndrome de respuesta inflamatoria sistémica (SIRS), con una mortalidad de hasta un $40 \%$ según lo reportado por van Natta, Klecka y $\operatorname{cols}^{2,4}$. Si bien existen aun controversias acerca de cuál es la técnica quirúrgica de elección y el mejor abordaje para el drenaje mediastínico, los autores concuerdan de que la mortalidad aumenta en forma importante si hay demora en su diagnóstico y no se realiza un drenaje quirúrgico precoz y agresivo ${ }^{5}$.

\section{Caso clínico}

Se presenta un paciente de sexo masculino de 25 años sin antecedentes mórbidos, que consultó por un cuadro de aproximadamente $24 \mathrm{~h}$ de evolución caracterizado por aumento de volumen de la región pectoral derecha, fiebre objetivada hasta $39^{\circ} \mathrm{C}$ y compromiso del estado general. En la anamnesis remota y dirigida destacaba que 12 días antes de la consulta presentó un traumatismo torácico contuso contralateral a la zona afectada actualmente. Al examen físico de ingreso destacaba febril $\left(39,2^{\circ} \mathrm{C}\right)$, taquicárdico $(95 \mathrm{pm})$ y presentaba un aumento de volumen sensible y fluctuante en relación al pectoral mayor derecho. Los exámenes de laboratorio corroboraron un cuadro infeccioso inflamatorio con una leucocitosis de $17,5 \times 10^{3} / \mathrm{ul}$, un recuento de baciliformes de 11\%, una VHS $86 \mathrm{~mm} / \mathrm{h}$, con PCR 235,68 (normal $<$ que $5,0 \mathrm{mg} / \mathrm{L}$ ). Se solicitaron imágenes donde se evidenció un ensanchamiento mediastínico en la radiografía de tórax y una tomografía computada (TC) de tórax que mostró AM con extensión a través de la pared torácica (Figura 1). Se administraron antibióticos empíricos $(2 \mathrm{~g}$ de Ceftriaxona + $600 \mathrm{mg}$ de Clindamicina iv). En la exploración quirúrgica mediante una mediastinotomía anterior derecha de Chamberlain, se obtuvo $+/-300 \mathrm{cc}$ de pus, evidenciando hacia medial la comunicación de la

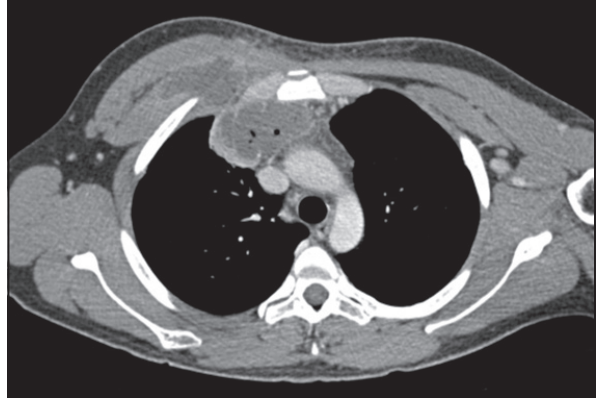

Figura 1a. Tomografía computada (TC) multicorte con contraste IV. Corte axial. Se demuestra una colección en el mediastino antero-superior asociado a un aumento de densidad del tejido adiposo adyacente, que se encuentra comunicado a través de la pared antero-lateral derecha con una colección ubicada en el espesor del músculo pectoral menor, el cual presenta burbujas en su interior.

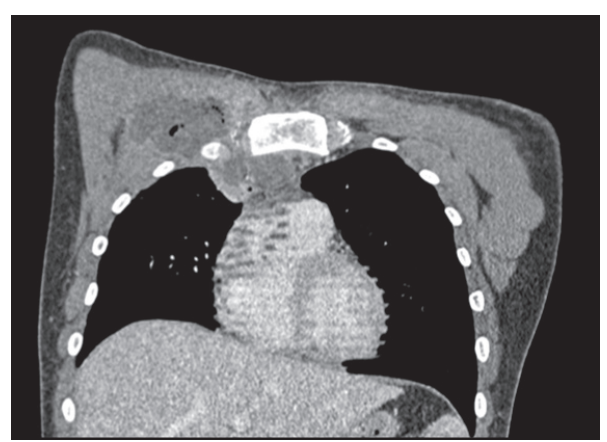

Figura 1b. Tomografía computada (TC) multicorte con contraste IV. Corte coronal. Se demuestra colección del mediastino antero-superior que se comunica hacia anterior a través de la región intercostal derecha con otra colección localizada a nivel del pectoral menor ipsilateral.

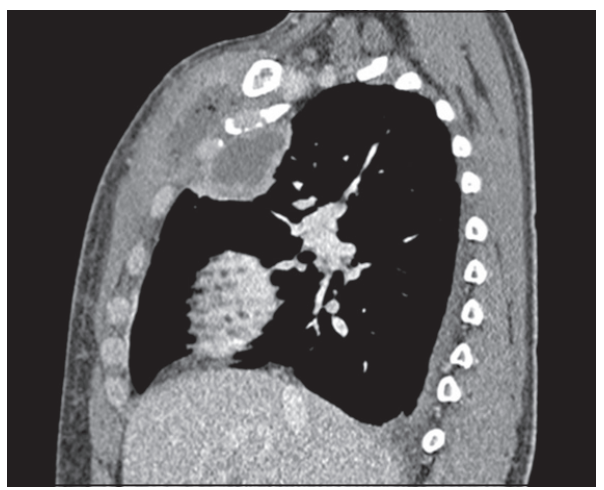

Figura 1c. Tomografía computada (TC) multicorte con contraste IV. Corte sagital. Colección en mediastino antero-superior que busca salida a través de la pared intercostal superior derecha asociándose a una colección a nivel del pectoral menor de ese lado. 
colección descrita con mediastino anterior. Digitalmente se debridó comunicando ampliamente ambas cavidades y se lavó con abundante solución fisiológica (Figura 2). Se dejaron drenajes tipo Penrose, uno al mediastino y otro a la región retro pectoral. Se envió tejido y líquido a cultivo de Koch, gérmenes aerobios y anaerobios. Desde el post operatorio inmediato, el paciente se mantuvo afebril, con descenso significativo de los parámetros inflamatorios a las $48 \mathrm{~h}$. A las $72 \mathrm{~h}$ se realizó traslape a tratamiento antibiótico oral con Amoxicilina/Ácido Clavulánico

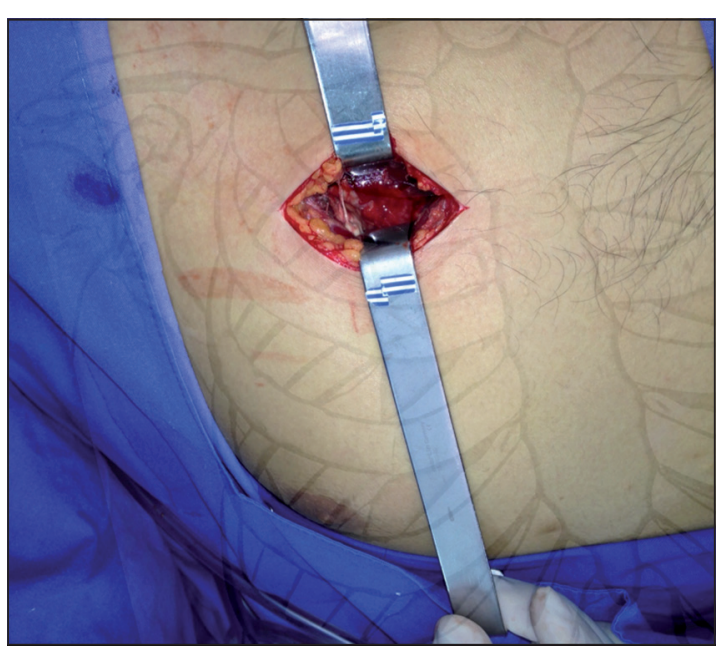

Figura 2. Imagen Cirugía, Mediastinotomía anterior o de Chamberlain con esquema anatómico.

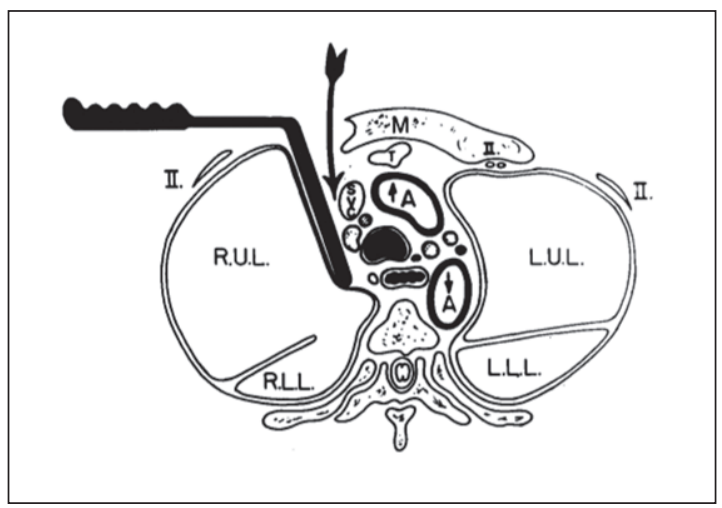

Figura 3. Sección horizontal del tórax a nivel del segundo cartílago costal visto desde abajo. El Timo se encuentra a veces primero. El segundo cartílago costal a la derecha es removido y la pleura se retrae lateralmente para permitir acceso a los linfonodos cercanos a la vena cava y a la tráquea ${ }^{7}$. Tomado de McNeill TM, Chamberlain JM. Diagnostic anterior mediastinotomy. The Annals of Thoracic Surgery 1966;2:532-9
$875 / 125 \mathrm{mg}$ cada $12 \mathrm{~h}$. El único resultado positivo de microbiología fue el cultivo de tejido y correspondió a un Staphylococcus aureus multi-sensible. No se evidenciaron infecciones en otro sitio y descartaron las causas de inmunosupresión más frecuentes. Paciente es dado de alta con curaciones diarias, a los 14 días se retiran los drenajes, a los 21 días se realiza TC de control que mostró resolución completa del cuadro; se suspenden los antibióticos al completar un mes de tratamiento.

\section{Discusión}

Los AM son una patología infrecuente y que muchas veces se diagnostica en forma tardía con un cuadro séptico avanzado. No existen muchos reportes de estos casos en la literatura, ni menos con compromiso a través de la pared torácica. A pesar de existir diversas causas de origen de los AM, en este caso existe la duda razonable si tuvo relación con el traumatismo torácico previo donde se haya infectado un hematoma mediastínico o fue un absceso de origen desconocido al igual que lo publicado por Kouritas y cols ${ }^{3}$, donde coincide tanto el germen aislado como el origen desconocido con el caso presentado.

Existen varios abordajes quirúrgicos para resolver esta patología. Si el compromiso mediastínico es alto el acceso cervical es el de elección, si existe compromiso bajo el manubrio esternal el abordaje debe ser por toracotomía clásica o videotoracoscopia $^{6}$. Estos últimos abordajes son de preferencia cuando ya existe un compromiso pleural asociado, para realizar una decorticación pleuropulmonar asociada al drenaje del mediastino. Sin embargo, en el caso presentado, no existía compromiso pleural y se optó por una mediastinotomía anterior o de Chamberlain ${ }^{7}$ para no contaminar el espacio pleural (Figura 3). Este abordaje en el lado derecho está ampliamente descrito en la literatura para biopsias de masas mediastínicas. En el lado izquierdo este abordaje se utiliza en la etapificación del cáncer pulmonar, pues permite acceder a los grupos ganglionares $5 \mathrm{y}$ 6 , lo que también se logra con una mediastinoscopia extendida, como la presentada por $\mathrm{Obiols}^{8}$, con una VATS o mediante TEMLA (transcervical extended mediastinal lymphadenectomy) ${ }^{9}$. Existen reportes de radiología intervencional con manejo de estos AM sólo con drenajes percutáneos ${ }^{10}$, lo cual está limitado en nuestro centro al no estar siempre disponible el recurso (radiólogos o drenajes necesarios). Este manejo puede ser como primer tratamiento o en el manejo postquirúrgico de colecciones residuales. En el caso de compromiso esternal, articulación condroesternal o esternoclavicular (que no fue el caso) se recomienda la remoción del foco de osteomielitis 
y cobertura con colgajos musculares, intercostales, serrato, pectoral, dorsal ancho y omental flap con o sin uso de VAC asociado ${ }^{11}$. La microbiología es variable, existen bastantes reportes donde el germen aislado fueron estafilococos y anaerobios ${ }^{4-5}$. En casos espontáneos hay que descartar fenómenos de inmunosupresión (HIV, desnutrición calórico proteica, diabetes, uso de corticoides, etc.) ya que la incidencia y complicaciones aumentan. Al ser una patología poco frecuente y los pacientes ser tan distintos unos de otros tampoco hay en la literatura una recomendación categórica de tipo de antibióticos y la duración de este.

En resumen, se trata de cuadros infrecuentes, muy graves si no son diagnosticados y tratados a tiempo. El manejo multidisciplinario asociado al drenaje quirúrgico o radiológico intervencional es esencial para mejorar el resultado y disminuir las complicaciones. La obtención de cultivos es mandatoria y muy útil para guiar el tratamiento. A diferencia de los cuadros pleurales, la evaluación del mediastino es más difícil en la radiografía simple por lo que uno debe controlar la evolución con una TC. Si se puede realizar un drenaje extra pleural satisfactorio éste es de elección. Finalmente, si bien está ampliamente descrito el concepto de "empiema necessitans" no existe descripción en la literatura de casos con "mediastinitis necessitans".

\section{Referencias}

1. Aronovitch M, Vineberg A. Two Cases of Anterior Mediastinal Abscess. Can Med Assoc J. 1945;53:455-8.

2. van Natta TL, Lemettoni MD. Thoracic: Acute necro- tizing mediastinitis. In: Pearson FG, Patterson, GA. Pearson's thoracic and esophageal surgery. 3rd ed. Philadelphia: Churchill Livingstone/Elsevier; 2008: 1521-28.

3. Kouritas VK, Zissis C, Bellenis I. Staphylococcal isolated anterosuperior mediastinal abscess of unknown origin. Interact Cardiovasc Thorac Surg. 2012;14:650-1.

4. Klecka J, Simanek V, Vodicka J, Spidlen V, Pradl R, Ferda JP. Acute mediastinitis-optimum diagnostic and therapeutic measures. Rozhl Chir. 2009;88:253-8.

5. Athanassiadi KA. Infections of the mediastinum. Thorac Surg Clin. 2009; 19:37-45.

6. Erkmen CP, Wang H, Czum J, Paydarfar JA. Use of cervicothoracic anatomy as a guide for directed drainage of descending necrotizing mediastinitis. Ann Thorac Surg. 2012;93:1293-4.

7. McNeill TM, Chamberlain JM. Diagnostic anterior mediastinotomy. The Annals of Thoracic Surgery 1966;2:532-9.

8. Obiols C, Call S, Rami-Porta R, Iglesias M, Saumench R, Serra-Mitjans M, et al. Extended cervical mediastinoscopy: mature results of a clinical protocol for staging bronchogenic carcinoma of the left lung. Eur J Cardiothorac Surg. 2012;41:1043-6.

9. Zieliński M. Video-assisted mediastinoscopic lymphadenectomy and transcervical extended mediastinal lymphadenectomy. Thorac Surg Clin. 2012;22:219-25.

10. Saxena P, Kumbhari V, Khashab MA. EUS-guided drainage of a mediastinal abscess. Gastrointest Endosc. 2014 Feb 17. pii: S0016-5107(13)02709-0.

11. Gallo O, Deganello A, Meccariello G, Spina R, Peris A. Vacuum-assisted closure for managing neck abscesses involving the mediastinum. Laryngoscope 2012;122:785-8. 